\title{
Psychological predictors of headache remission in children and adolescents
}

This article was published in the following Dove Press journal:

Adolescent Health, Medicine and Therapeutics

21 April 2016

Number of times this article has been viewed

\author{
Marcel Carasco \\ Birgit Kröner-Herwig \\ Department of Clinical Psychology \\ and Psychotherapy, Georg-Elias- \\ Müller-Institut für Psychologie, \\ Georg-August-Universität Göttingen, \\ Göttingen, Germany
}

Objective: Longitudinal studies on headaches often focus on the identification of risk factors for headache occurrence or "chronification". This study in particular examines psychological variables as potential predictors of headache remission in children and adolescents.

Methods: Data on biological, social, and psychological variables were gathered by questionnaire as part of a large population-based study $(\mathrm{N}=5,474)$. Children aged 9 to 15 years who suffered from weekly headaches were selected for this study sample, N=509. A logistic regression analysis was conducted with remission as the dependent variable. In the first step sex, age, headache type, and parental headache history were entered as the control variables as some data already existed showing their predictive power. Psychological factors (dysfunctional coping strategies, internalizing symptoms, externalizing symptoms, anxiety sensitivity, somatosensory amplification) were entered in the second step to evaluate their additional predictive value.

Results: Highly dysfunctional coping strategies reduced the relative probability of headache remission. All other selected psychological variables reached no significance, ie, did not contribute additionally to the explanation of variance of the basic model containing sex and headache type. Surprisingly, parental headache and age were not predictive. The model explained only a small proportion of the variance regarding headache remission $\left(R^{2}=0.09\right.$ [Nagelkerke]).

Conclusion: Successful coping with stress in general contributed to remission of pediatric headache after 2 years in children aged between 9 and 15 years. Psychological characteristics in general had only small predictive value. The issue of remission definitely needs more scientific attention in empirical studies.

Keywords: headache disorders, children, remission, psychological factors, longitudinal study, prediction

\section{Introduction \\ Biopsychosocial pain model}

Biological, psychological, and social factors play an important role in the development and perpetuation of pain. ${ }^{1,2}$ The significance of psychosocial factors was demonstrated in several studies. ${ }^{3-5}$ Besides biological (hereditary) factors, cognitive, emotional, and behavioral variables play an important role in explaining the occurrence of pediatric headache. ${ }^{2,6,7}$ A 2012 study based on the same original dataset found a correlation between internalizing symptoms, anxiety sensitivity, self-acceptance, and somatosensory amplification (SSA) with pediatric headache. ${ }^{3}$
Correspondence: Birgit Kröner-Herwig Georg-August-University Göttingen, Georg-Elias-Müller-Institute of Psychology, Department of Clinical Psychology and Psychotherapy, Gosslerstr I4, 37073 Göttingen, Germany Tel +4955I 393358 I

Email bkroene@uni-goettingen.de accessing the work you hereby accept the Terms. Non-commercial uses of the work are permitted without any further permission from Dove Medical Press Limited, provided the work is properly

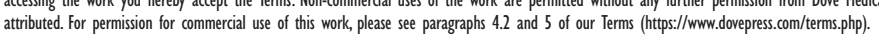

Dovepress

http://dx.doi.org/10.2147/AHMT.S97925 


\section{Headache remission}

Only very few studies dealing with predictors of headache remission were found in the literature search. One longitudinal study tried to identify biological predictors of migraine remission with onset in childhood or adolescence. ${ }^{8}$ No significant predictors emerged in this clinical trial on 137 patients aged 3 to 17 years. A population-based study with 1,134 adult participants found "being married" and "diagnosed with diabetes" as positive predictors for the remission of daily headache which was a quite unexpected finding. ${ }^{9}$

An examination of psychological factors as potential predictors for headache remission in children and adolescents so far had not been undertaken. Our prospective study examined whether selected psychological variables can explain additional variance regarding remission above certain control variables, for which some evidence had already been found regarding a remission of weekly headache in children and adolescents.

\section{Control variables}

\section{Sex}

There are sex differences regarding the prevalence as well as the risk factors for the incidence of headache. ${ }^{10-12}$ Female sex is a risk factor for the chronification of headache. ${ }^{13} \mathrm{~A}$ higher persistence of headache in girls versus boys was found in a population-based study with 2,025 participating children. ${ }^{14}$ Thus, a higher remission rate for boys compared to girls was expected.

\section{Age}

Increasing age of children is associated with an increase in headache prevalence. ${ }^{10,15}$ No studies addressing the possible association of age and remission of pediatric headache were found. We decided to include age into the model as an exploratory control variable.

\section{Types of headache}

Different predictors of incidence and prognosis were found for migraine and tension type headache (TTH) ${ }^{16,17}$ In an 8 -year follow-up on a clinical trial including 100 children aged 4 to 18 years, Guidetti and Galli found a higher probability for the remission of TTH than for migraine. ${ }^{18}$ Another longitudinal study with a 20-year follow-up found the same results in a sample of 60 children: remission was observed in only $19 \%$ of the patients with migraine compared to a remission rate of $53 \%$ for TTH. ${ }^{19}$ In this study, a higher remission rate was expected for TTH compared to migraine.

\section{Parental headaches}

Parental headache can have an effect on the child on a biological as well as on a social level. On the one hand, serving as a role model, parents influence their child's headache through the way they react to their own headache. ${ }^{20}$ On the other hand, a distinct genetic influence in headaches has been shown. ${ }^{21}$

Children whose parents suffer from headaches, have a higher probability to develop headaches themselves., 32,23 A longitudinal study on a population-based sample of 55 adolescents revealed a lower remission rate of migraine, if an immediate family member also suffers from migraine. ${ }^{24}$ Thus, a negative correlation between parental headache and the remission of pediatric headache was to be expected.

\section{Psychological predictors Stress coping}

Coping can be understood as the cognitive and behavioral effort to resolve a stressful situation. ${ }^{25,26}$ A connection between stress and pain exists, and is moderated by the way people cope with and react to pain. ${ }^{27}$ Dysfunctional coping can contribute to the persistence of pain, as children are not able to reduce the negative impact of stress on their pain experience. ${ }^{4,28}$ Passive and avoiding coping strategies can be seen as dysfunctional and are expected to reduce the probability of headache remission.

\section{Internalizing symptoms}

Following the definition of Achenbach, ${ }^{29}$ internalizing symptoms primarily include anxiety and depressive symptoms. A rather strong association between internalizing symptoms and pediatric headache was found in various studies. ${ }^{3,16}$ A higher level of internalizing symptoms was assumed to be associated with a lower chance for remission.

\section{Externalizing symptoms}

Externalizing symptoms in children, including aggressive behavior, anger, and hyperactivity, are correlated with headache. ${ }^{3,29}$ A connection between externalizing symptoms and the incidence ${ }^{30}$ and prevalence ${ }^{3}$ of pediatric headache has already been demonstrated in quite a few studies. We predicted a lower chance for remission in children with a higher level of externalizing symptoms.

\section{Anxiety sensitivity}

Anxiety sensitivity is a theoretical construct describing the fear of sensations associated with anxiety as symptoms of sympathetic activation are interpreted as dangerous and harmful. ${ }^{31}$ They are experienced as aversive and induce anxiety. ${ }^{32}$ 
A positive correlation between anxiety sensitivity and the incidence of headache has been shown in several studies. ${ }^{33-35}$ A possible connection between anxiety sensitivity and remission of headache seemed possible and was therefore examined.

\section{SSA}

SSA is a neighboring construct described as a tendency to experience somatic sensations as being particularly strong and disturbing. ${ }^{36}$ Earlier studies mainly examined the connection between SSA and chronic pain in adults. ${ }^{37,38} \mathrm{~A}$ connection between SSA and the prevalence of headache in children seems to exist. ${ }^{3}$ Our study aims at examining its contribution to headache remission for the first time.

\section{Methods}

\section{Study design and sample}

This study is part of the project "Children, adolescents and headache" conducted at the University of Göttingen, Germany. For this epidemiological longitudinal study, a total of 8,800 families having at least one child aged between 7 and 14 years, were randomly chosen from the public registries. Starting in the year 2003, these families received four yearly questionnaires addressed to the children as well as to the parents. The participants were asked to answer questions concerning their headaches, other pain, pain-related behaviors, and various psychosocial factors and conditions. The study design was approved by the ethical commission of the German Society for Psychology. Parents and children were fully informed about the research issues and study procedures. They were free to take part in the study and implied consent by sending in the questionnaires by mail. A more detailed description of the study design can be found in the article by KrönerHerwig et al. ${ }^{39}$

Only children (at least 9 years old) having completed their own questionnaire and with a matching parental questionnaire available were included. From this original dataset, a subset of the children suffering from weekly headache in wave two was selected. Cases with incomplete or inconsistent data were excluded (Figure 1). The selected sample consisted of $\mathrm{N}=509$ children; $61.5 \%$ female and $38.5 \%$ male. The mean age was $M=12.0$ years (standard deviation $=1.1$ years). The youngest child in wave 2 was

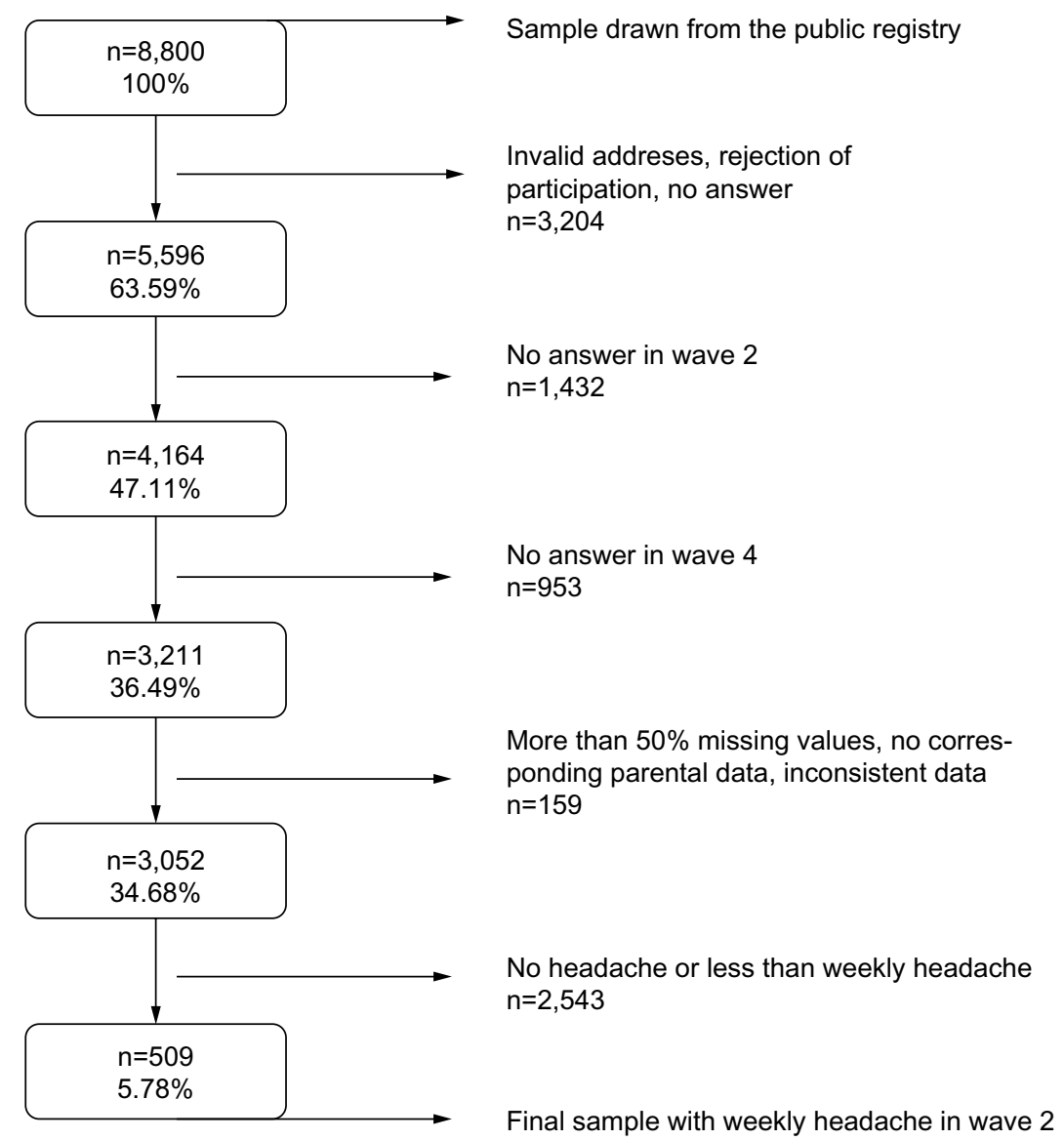

Figure I Sample selection. 
9 years old and the oldest was 15 years old. The sample size can vary in different analyses due to missing values in the variables of interest.

\section{Operationalization of the dependent variable "headache"}

The participating children were asked whether they had ever experienced headaches during the last 6 months. If they had, information regarding frequency, intensity, duration, and accompanying symptoms was assessed. The questionnaire was designed based on systematics of the second edition of the International Classification of Headache Disorders (ICHD-II; IHS, 2004). It allowed a differentiation between migraine and $\mathrm{TTH}^{40}$

The 505 children having had at least one headache per week in wave two (6-month reference period) constituted the sample of "recurrent headache" examined for remission in wave 4 ( 2 years later). Remission was defined by the response "no headaches" or "less than once per month" (in wave 4). Otherwise the category "no remission" was attributed.

\section{Operationalization of the predictors} Control variables

The data from the parental questionnaire (wave 1) were used to determine sex and age of the children. Headache type of the children was operationalized following the criteria of the ICHD-II. ${ }^{41}$ Only migraine and TTH were differentiated leaving a category of "uncategorizable headache", not fulfilling one or more criteria for migraine or TTH.

Parental headache was defined as a binary variable with the categories "at least weekly headache" and "less than weekly headache". Data from the parental self-report questionnaire were used where parents had been asked about their headache frequency on a 4-point scale ranging from "no headache" to "at least weekly headache".

\section{Psychological variables: dysfunctional coping,} internalizing, externalizing, anxiety sensitivity, and SSA A limited number of items were taken from the the original validated psychometric tests (eg, Stresscoping test) because it was not practical to include the complete tests, and used for the assessment of these trait variables. Instead, a subsample of items were extracted from tests based on their item test correlation. Good to satisfying homogeneity of the shortened scales was found. ${ }^{3}$ In a subsample of 250 children, high correlations of the shortened and the complete versions of the different scales $(0.74 \leq r \leq 0.96)$ were demonstrated. ${ }^{23}$
Dysfunctional coping was defined as a high score on the "habitual negative coping style" scale consisting of five items from the "Stressverarbeitungsfragebogen" (stress coping questionnaire). ${ }^{42}$ Two items referred to aggression and one item each to passive avoidance, continued mental preoccupation, and resignation. The internal consistency of the shortened scale reached an $\alpha=0.76 .{ }^{3}$

Information on internalizing and externalizing symptoms was collected using items from the Youth Self Report. ${ }^{43}$ Eight items referring to anxiety/depression were selected from the sub-scale for internalizing symptoms. Six items referring to hyperactivity and aggressive behavior were taken from the sub-scale for externalizing disorders. The original 3-point scale of the items was transformed into a 5-point scale to guarantee better comparability with the other items of the questionnaire. With a Cronbach's alpha of 0.9 for internalizing and 0.8 for externalizing symptoms, the scales showed a high internal consistency. ${ }^{3}$

Five items selected from the Anxiety Sensitivity Index ${ }^{44}$ were used to assess the anxiety sensitivity of the children $(\alpha=0.7){ }^{3}$ SSA was assessed using four items from the Somatosensory Amplification Scale ${ }^{45}$ asking the children about their personal impairment caused by unpleasant somatic sensations. However, the internal consistency of this scale was not fully satisfactory $(\alpha=0.6){ }^{3}$

\section{Statistical analysis}

The main analysis consisted of a multiple logistic regression with "remission" as the dependent variable. Following Hosmer and Lemeshow, ${ }^{46}$ at least ten subjects per parameter of the regression model are required in each category of the dependent variable. In the present sample, 109 subjects belonged to the category "remission", 368 children did not show headache remission in wave 4 . Consequently, a maximum of nine predictors could be included in the analysis. According to the theoretical reflections presented earlier, the following predictors were included: the four control variables sex, age, headache type, and parental headache were included in a first block, and the five psychological predictors anxiety sensitivity, SSA, dysfunctional coping, internalizing, and externalizing symptoms in a second one. Medication (preventive/abortive) was not used in the regression analysis, since it did not correlate significantly with the dependent variable (all $P<0.20$ ). Being a partly exploratory analysis, a stepwise (backward) procedure was used as recommended by Field. ${ }^{47}$

All analyses were conducted using IBM SPSS Statistics 21 (IBM Corporation, Armonk, NY, USA). The significance threshold was set at $P=0.05$ for all analyses. 
Table I Prevalence and remission rates depending on sex and headache type (\%)

\begin{tabular}{llllllll}
\hline & Total & \multicolumn{2}{l}{ Sex } & & \multicolumn{3}{c}{ Headache type } \\
\cline { 3 - 4 } \cline { 6 - 8 } \cline { 6 - 8 } & & Male & Female & & TTH & MIG & NCH \\
\hline Prevalence & 19.75 & 15.51 & 23.84 & & 7.77 & 4.19 & 7.84 \\
Remission rate & 22.85 & 31.77 & 17.26 & & 21.24 & 13.08 & 29.65
\end{tabular}

Abbreviations: TTH, tension type headache; MIG, migraine; $\mathrm{NCH}$, noncategorizable headache.

\section{Results \\ Descriptive data}

In the original sample in wave 2 ( $\mathrm{n}=4,164$; Figure 1) $19.8 \%$ were suffering from at least weekly headache in the past 6 months. More girls were suffering from headaches $(23.8 \%)$ than boys $(15.5 \%)$. TTH occurred in $7.8 \%$ of the subjects, migraine in $4.2 \%$ and non-categorizable headache was found in $7.8 \%$ (Table 1 ).

At the wave 4 assessment time-point, remission had occurred in 109 children equating to a remission rate of $23.9 \%$. The remission rate was higher in boys $(31.8 \%)$ than in girls (17.3\%). Remission rates were lowest for migraine (13.1\%), higher for TTH (21.2\%), and highest for noncategorizable headache (Table 1). The mean values of the psychological variables were found in the low and middle range of the 5-point rating scales (1.53 $\leq M \leq 2.4$; Table 2$)$.

\section{Results of the logistic regression}

The regression model explained $9 \%$ of the observed variance in the variable remission (Nagelkerke $=0.09$; Table 3 ). Sex was a significant predictor of headache remission. The probability of remission was twice as high for boys than girls (odds ratio $[\mathrm{OR}]=2.18 ; P=0.001$ ). Headache type also predicted headache remission. A remission was approximately 1.8 times less probable for TTH $(\mathrm{OR}=0.6 ; P=0.02)$ and approximately 2.6 times less probable for migraine compared to non-categorizable headache (Table 3). Age and parental headache were not significant predictors of headache remission and thus not included in the model.

Table 2 Psychological predictors: descriptive statistics

\begin{tabular}{lllll}
\hline Predictors & $\mathbf{N}$ & $\mathbf{M}^{\#}$ & SD & Min-Max \\
\hline NH coping style & 502 & 2.39 & 0.77 & $1.00-4.80$ \\
INT symptoms & 495 & 1.87 & 0.65 & $1.00-4.25$ \\
EXT symptoms & 492 & 1.84 & 0.56 & $1.00-3.88$ \\
AS & 505 & 1.53 & 0.58 & $1.00-4.50$ \\
SSA & 505 & 2.02 & 0.66 & $1.00-5.00$ \\
\hline
\end{tabular}

Note: "Data are mean item score of the specific variable, 5 -point rating scales. Abbreviations: NH, negative habitual; INT, internalizing; EXT, externalizing; AS, anxiety sensitivity; SSA, somatosensory amplification; M, mean; SD, standard deviation; Min, minimum; Max, maximum.
Table 3 Logistic regression model with the included predictors $(P \leq 0.05)$

\begin{tabular}{llll}
\hline Predictors & B (SD) & P-value & Odds ratio (95\% Cl) \\
\hline Constant & $-1.1 I(0.20)$ & & \\
Sex (ref: female) & $0.78(0.23)$ & $0.00 I$ & $2.18(1.38-3.42)$ \\
TTH (ref: other headache) & $-0.60(0.25)$ & 0.018 & $0.55(0.34-0.90)$ \\
MIG (ref: other headache) & $-0.96(0.34)$ & 0.004 & $0.38(0.20-0.74)$ \\
NH coping style & $-0.24(0.12)$ & 0.039 & $0.78(0.62-0.99)$ \\
Total model & $\chi^{2}(6)=30.00, P<0.001 ; R^{2}=0.09$ (Nagelkerke) \\
\hline
\end{tabular}

Note: Multiple logistic regression analysis with "remission" as dependent variable using a stepwise (backward) procedure with two blocks was performed.

Abbreviations: TTH, tension type headache; MIG, migraine; NH, negative habitual; ref, reference category; SD, standard deviation.

Of the five psychological predictors that were considered, only dysfunctional coping contributed to the prediction of headache remission $(\mathrm{OR}=0.8 ; P=0.04)$. A reduction by 1 point on the scale for negative habitual coping styles was associated with a 1.3 times higher probability for headache remission (Table 3).

All predictors were analyzed for multi-collinearity using the variance inflation factors. All variance inflation factors showed values smaller than 10. Following Field, ${ }^{47}$ multicollinearity was no problem in this analysis. The highest correlation between two predictors was found between negative habitual coping style and internalizing symptoms, $r=0.7 ; P<0.01$. All other correlations were smaller than $r=0.50$ (Table 4).

\section{Discussion}

\section{Key results and interpretation}

As expected, a significant association between the remission of pediatric headache and the control variables sex and headache type was confirmed. Male sex was a positive predictor of headache remission, ie, boys tended to show more headache remission than girls. The higher probability of remission in boys compared to girls matches the findings of Laurell et al. ${ }^{48}$ Additionally, incidence and prevalence rates are higher in girls than in boys. ${ }^{10-12}$ The unfavorable prognosis for migraine compared to TTH and other types of headache also matches the findings in other studies. ${ }^{18,19}$ In general, headache is a bigger problem in girls than in boys. Remission is less probable for migraine as compared to TTH. A headache syndrome not fulfilling the criteria of migraine nor TTH had the best chances for remission in this study.

Against all expectations, no connection between age and parental headache with headache remission was found. The observation of Monastero et $\mathrm{al}^{24}$ that a lower probability of migraine remission is associated with having a parent who is also suffering from headaches were not confirmed by our 
Table 4 Intercorrelations of all predictors and control variables

\begin{tabular}{|c|c|c|c|c|c|c|c|c|c|}
\hline Predictors & I & 2 & 3 & 4 & 5 & 6 & 7 & 8 & 9 \\
\hline I. Sex & - & $0.10^{*}$ & 0.05 & -0.05 & $0.23 * *$ & $0.28 * *$ & $-0.14 * *$ & $0.17 * *$ & $0.12 * *$ \\
\hline 2. Age & & - & 0.01 & 0.06 & $0.25 * *$ & $0.25 * *$ & $0.20 * *$ & 0.03 & 0.06 \\
\hline 3. Headache type & & & - & -0.05 & $0.14^{* *}$ & $0.13^{* *}$ & 0.02 & $0.14 * *$ & $0.16 * *$ \\
\hline 4. Parental headache & & & & - & 0.05 & 0.03 & 0.03 & 0.06 & 0.01 \\
\hline 5. NH coping style & & & & & - & $0.68 * *$ & $0.2 I^{* *}$ & $0.29 * *$ & $0.40 * *$ \\
\hline 6. INT & & & & & & - & $0.23^{* *}$ & $0.38 * *$ & $0.40 * *$ \\
\hline 7. EXT & & & & & & & - & 0.02 & $0.09 *$ \\
\hline 8. AS & & & & & & & & - & $0.44 * *$ \\
\hline 9. SSA & & & & & & & & & - \\
\hline
\end{tabular}

Note: $* P \leq 0.05, * * P \leq 0.01$.

Abbreviations: NH, negative habitual; INT, internalizing; EXT, externalizing; AS, anxiety sensitivity; SSA, somatosensory amplification.

data. A familial influence on remission was neither seen in tension type nor in non-catagorizable headache. A correlation between increasing age and increasing prevalence ${ }^{10,15}$ and a lower success rate of therapeutic intervention ${ }^{49}$ had been shown, but no correlation with headache remission could be demonstrated in this study.

While none of the other considered psychological variables (internalizing and externalizing symptoms, anxiety sensitivity, and SSA) contributed significantly to the prediction of headache remission, dysfunctional coping with stress was identified as a predictor. The less dysfunctional coping strategies children reported at the assessment time, the more probable was a remission of their headache. This regression model was able to explain $9 \%$ of the variance of the dependent variable "remission", $R^{2}=0.09$ (Nagelkerke) compared to $8 \%$ explained by the model containing only the control variables.

Coping with stress is the only psychological predictor of headache remission that could be confirmed by this study. If stress cannot be resolved in an adequate way and a negative coping style is frequently used, the probability of headache remission is significantly reduced. Inversely, the use of adequate coping strategies should increase the probability of headache remission. This finding supports the ideas of Houle and Nash expressed in their review ${ }^{50}$ of a close connection between stress and headache. They particularly consider stress as a main factor for the chronification of headache. These findings point to the important role of relaxation techniques and teaching of coping strategies in the treatment of headaches, which have already been integrated as part of different therapeutic programs aiming at headache improvement. ${ }^{51} \mathrm{~A}$ metaanalysis conducted by Trautmann et al found that relaxation techniques were used in $27 \%$ of the included studies. ${ }^{52}$

\section{Limitations}

The regression model presented in this study only explains a rather small part of the variance observed regarding headache remission. Thus, the psychological predictors having been measured 2 years before the critical assessment period of remission did not have a large impact on this procedural feature of headache. It must be assumed that a lot of factors not considered in this study might also play an important role. Headache remission seems to be a phenomenon influenced by a complex combination of biological, social, and psychological factors, but methodological considerations prohibited the inclusion of more possible predictors.

The final sample consisting of 509 children is relatively small for two reasons: we chose a relatively strict criterion for remission. To ensure that headache affection at baseline was of clinical significance, only children with at least weekly episodes were included, and only a less than monthly headache was allowed at the second assessment. The second reason relates to the 2-year instead of 1-year interval regarding the assessment of remission, which increases the general dropout rate in the long term compared to a 1-year period. Due to the size of the sample, differential analysis regarding sex or headache type did not appear appropriate on a statistical level. Still, the predictors (or their impact) for pediatric headache remission might differ depending on sex and headache type.

A possible methodological problem arises from the use of retrospective questionnaires asking about headache experiences during the last 6 months. A study comparing headache diaries and questionnaires showed that children tend to overestimate the intensity and duration of headache in retrospective questionnaires..$^{53}$ The retrospective assessment of headaches may have resulted in distorted prevalence ${ }^{14}$ and remission rates. However, the use of a binary-dependent variable should have reduced the error induced variance. An assessment using diaries instead of questionnaires as recommended by Van den Brink et al, ${ }^{53}$ would have demanded a half year of selfmonitoring in each of the two study periods, which without doubt would have reduced the respondents to nearly nil, given that no bonus for the participants could be offered. 
The different predictors had been tested for multicollinearity before conducting the logistic regression. Even though the values of the variance inflation factor did not indicate a multi-collinearity problem following the criteria of Field, ${ }^{47}$ the relatively high correlation between the two predictors "negative habitual coping style" and "internalizing symptoms" needs to be considered. This high correlation can be explained by the operationalization of the two predictors: the traits "passive avoidance", "continued mental preoccupation", and "resignation" overlap considerably with depression contained in the variable "internalizing symptoms". Possibly, "internalizing symptoms" could have been a significant predictor in a model without the predictor "negative habitual coping styles". Nevertheless, "negative habitual coping style" is obviously the stronger predictor in this dataset.

Altogether, pediatric headache remission is difficult to predict. The selected psychological variables had only little prognostic value under these particular assessment conditions. We obviously need many more research attempts to explore influencing factors of headache remissions in different age grades, with different headache types, over different time intervals, in different samples, and with different biopsychosocial variables as predictors.

\section{Acknowledgments}

The research project has been supported by a grant from the German Ministry of Education and Research within the German Headache Consortium.

\section{Disclosure}

The authors report no conflicts of interest in this work.

\section{References}

1. Basler HD, Franz C, Kröner-Herwig B. Psychologische Schmerztherapie: Grundlagen-Diagnostik-Krankheitsbilder-Schmerz-Psychotherapie. [Psychological Pain Therapy: Basics, diagnosis, pain syndromes, psychotherapy]. Heidelberg: Springer; 2004. German.

2. Kröner-Herwig B. Schmerz als biopsychosoziales Phänomen - eine Einführung. [Pain as a biopsychosocial phenomenon. An introduction]. In: Kröner-Herwig B, Frettlöh J, Klinger R, Nilges P, editors. Schmerz-psychotherapie. [Pain Psychotherapy]. Heidelberg: Springer; 2011:541-563. German.

3. Kröner-Herwig B, Gassmann J. Headache disorders in children and adolescents: their association with psychological, behavioral, and socioenvironmental factors. Headache. 2012;52(9):1387-1401.

4. McGrath PA, Hillier LM. Recurrent headache: triggers, causes, and contributing factors. Prog Pain Res Manag. 2001;19:77-107.

5. Roth-Isigkeit A, Thyen U, Stöven H, Schwarzenberger J, Schmucker P. Pain among children and adolescents: restrictions in daily living and triggering factors. Pediatrics. 2005;115(2):e152-e162.

6. Gaßmann J. Kopfschmerzen bei Kindern und Jugendlichen: Verlauf und Risikofaktoren. [Headache in children and adolescents: course and risk factors]. [dissertation]. Göttingen: Georg-August-Universität; 2009. German.
7. Gassmann J, Morris L, Heinrich M, Kröner-Herwig B. One-year course of paediatric headache in children and adolescents aged 8-15 years. Cephalalgia. 2008;28(11):1154-1162.

8. Termine C, Ferri M, Livetti G, et al. Migraine with aura with onset in childhood and adolescence: long-term natural history and prognostic factors. Cephalalgia. 2010;30(6):674-681.

9. Scher AI, Stewart WF, Ricci JA, Lipton RB. Factors associated with the onset and remission of chronic daily headache in a population-based study. Pain. 2003;106(1):81-89.

10. Abu-Arafeh I, Razak S, Sivaraman B, Graham C. Prevalence of headache and migraine in children and adolescents: a systematic review of population-based studies. Dev Med Child Neurol. 2010;52(12): 1088-1097.

11. Gaßmann J, Barke A, van Gessel H, Kröner-Herwig B. Sex-specific predictor analyses for the incidence of recurrent headaches in German schoolchildren. Psychosocial Med. 2012;9:Doc03.

12. Gaßmann J, Vath N, van Gessel H, Kröner-Herwig B. Risk factors for headache in children. Dtsch Ärztebl Int. 2009;106(31-32):509-516.

13. Kienbacher $\mathrm{CH}$, Wöber $\mathrm{CH}$, Zesch HE, et al. Clinical features, classification and prognosis of migraine and tension-type headache in children and adolescents: a long-term follow-up study. Cephalalgia. 2006;26(7):820-830.

14. van Gessel H, Gaßmann J, Kröner-Herwig B. Children in pain: recurrent back pain, abdominal pain, and headache in children and adolescents in a four-year-period. J Pediatr. 2011;158(6):977-983.e1-e2.

15. Fendrich K, Vennemann M, Pfaffenrath V, et al. Headache prevalence among adolescents-the German DMKG headache study. Cephalalgia. 2007;27(4):347-354.

16. Anttila P, Sourander A, Metsähonkala L, Aromaa M, Helenius H, Sillanpää M. Psychiatric symptoms in children with primary headache. J Am Acad Child Adolesc Psychiatry. 2004;43(4):412-419.

17. Karwautz A, Wöber C, Lang T, et al. Psychosocial factors in children and adolescents with migraine and tension-type headache: a controlled study and review of the literature. Cephalalgia. 1999;19(1): $32-43$.

18. Guidetti V, Galli F. Evolution of headache in childhood and adolescence: an 8-year follow-up. Cephalalgia. 1998;18(7):449-454.

19. Brna P, Dooley J, Gordon K, Dewan T. The prognosis of childhood headache: a 20-year follow-up. Arch Pediatr Adolesc Med. 2005; 159(12):1157-1160.

20. Goubert L, Vlaeyen JW, Crombez G, Craig KD. Learning about pain from others: an observational learning account. J Pain. 2011;12(2):167-174.

21. McGrath P. Headache in children: the nature of the problem. In: McGrath P, Hillier L, editors. The Child with Headache: Diagnosis and Treatment. Progress in Pain Research and Management. Seattle: IASP Press; 2001:29-56. German.

22. Bandell-Hoekstra I, Abu-Saad HH, Passchier J, Knipschild P. Recurrent headache, coping, and quality of life in children: a review. Headache. 2000;40(5):357-370.

23. Kröner-Herwig B, Morris L, Heinrich M. Biopsychosocial correlates of headache: what predicts pediatric headache occurrence. Headache 2008;48(4):529-544.

24. Monastero R, Camarda C, Pipia C, Camarda, R. Prognosis of migraine headaches in adolescents: a 10-year follow-up study. Neurology. 2006;67(8):1353-1356.

25. Lazarus RS. Psychological Stress and the Coping Process. New York: McGraw-Hill; 1996

26. Lazarus RS, Folkman S. Stress, Appraisal, and Coping. New York: Springer; 1984.

27. Kröner-Herwig B, Pothmann R. Schmerz bei Kindern. In: KrönerHerwig B, Frettlöh J, Klinger R, Nilges P, editors. Schmerzpsychotherapie. [Pain Psychotherapy]. Heidelberg: Springer; 2007:171-193. German

28. Weickgenant AL, Slater MA, Patterson TL, Atkinson JH, Grant I, Garfin SR. Coping activities in chronic low back pain: relationship with depression. Pain. 1993;53(1):95-103. 
29. Achenbach TM. The classification of children's psychiatric symptoms: a factor-analytic study. Psychol Monogr. 1966;80(7):1-37.

30. Virtanen R, Aromaa M, Koskenvuo M, et al. Externalizing problem behaviors and headache: a follow-up study of adolescent Finnish twins. Pediatrics. 2004;114(4):981-987.

31. Reiss S, Peterson RA, Gursky DM, McNally RJ. Anxiety sensitivity, anxiety frequency, and the prediction of fearfulness. Behav Res Ther. 1986;24(1):1-8.

32. Kemper CJ. Das Persönlichkeitsmerkmal Angstsensitivität: Taxon oder Dimension? - Eine Analyse mit dem Mischverteilungs-Raschmodell. [The personality feature anxiety sensitivity: taxon or dimension: an analysis with the Rasch model]. Hamburg: Kovac; 2010. German.

33. Fuss S, Pagé MG, Katz J. Persistent pain in a community-based sample of children and adolescents: sex differences in psychological constructs. Pain Res Manag. 2011;16(5):303-309.

34. Martin AL, McGrath PA, Brown SC, Katz J. Anxiety sensitivity, fear of pain and pain-related disability in children and adolescents with chronic pain. Pain Res Manag. 2007;12(4):267-272.

35. Tsao JC, Allen LB, Evans S, Lu Q, Myers CD, Zeltzer LK. Anxiety sensitivity and catastrophizing associations with pain and somatization in non-clinical children. J Health Psychol. 2009;14(8):1085-1094.

36. Barsky AJ, Goodson JD, Lane RS, Cleary PD. The amplification of somatic symptoms. Psychosom Med. 1988;50(5):510-519.

37. Gregory R, Manring J, Wade M. Personality traits related to chronic pain location. Ann Clin Psychiatry. 2005;17(2):59-64.

38. Raphael KG, Marbach JJ, Gallagher RM. Somatosensory amplification and affective inhibition are elevated in myofascial face pain. Pain Med. 2000;1(3):247-253.

39. Kröner-Herwig B, Heinrich M, Morris L. Headache in German children and adolescents: a population-based epidemiological study. Cephalalgia. 2007;27(6):519-527.

40. Heinrich M, Morris L, Kröner-Herwig B. Self-report of headache in children and adolescents in Germany: possibilities and confines of questionnaire data for headache classification. Cephalalgia. 2009;29(8):864-872.

41. Headache Classification Subcommittee of the International Headache Society. The International Classification of Headache Disorders: 2nd edition. Cephalalgia. 2004;24 (Suppl 1):9-160.
42. Janke W, Erdmann G, Kallus KW. Streßverarbeitungsfragebogen (SVF) mit SVF 120. [The stress-coping inventory]. Göttingen: Hogrefe; 1997. German.

43. Achenbach TM. Manual for the Youth Self-report and 1991 Profile. Burlington: University of Vermont, Department of Psychiatry; 1991.

44. Peterson RA, Reiss S. Anxiety Sensitivity Index Manual. 2nd ed. Worthington, OH: International Diagnostic Systems; 1993.

45. Barsky AJ, Wyshak G, Klerman GL. The somatosensory amplification scale and its relationship to hypochondriasis. J Psychiatr Res. 1990; 24(4):323-334.

46. Hosmer DW, Lemeshow S. Applied Logistic Regression (Second Edition). New York: John Wiley and Sons; 2000.

47. Field A. Discovering Statistics using SPSS. 3rd ed. London: Sage; 2009.

48. Laurell K, Larsson B, Mattsson P, Eeg-Olofsson O. A 3-year followup of headache diagnoses and symptoms in Swedish schoolchildren. Cephalalgia. 2006;26(7):809-815.

49. Hermann C, Blanchard EB, Flor H. Biofeedback treatment for pediatric migraine: prediction of treatment outcome. J Consult Clin Psychol. 1997;65(4):611-616.

50. Houle T, Nash JM. Stress and headache chronification. Headache. 2008;48(1):40-44.

51. Kröner-Herwig B, Frettlöh J. Behandlung chronischer Schmerzsyndrome: Plädoyer für einen interdisziplinären Therapieansatz. In: Kröner-Herwig B, Frettlöh J, Klinger R, Nilges P, editors. Schmerzpsychotherapie. [Pain Psychotherapy]. Heidelberg: Springer; 2011:3-14. German.

52. Trautmann E, Lackschewitz H, Kröner-Herwig B. Psychological treatment of recurrent headache in children and adolescents - a metaanalysis. Cephalalgia. 2006;26(12):1411-1414.

53. Van den Brink M, Bandell-Hoekstra EN, Abu-Saad HH. The occurrence of recall bias in pediatric headache: a comparison of questionnaire and diary data. Headache. 2001;41(1): 11-20.
Adolescent Health, Medicine and Therapeutics

\section{Publish your work in this journal}

Adolescent Health, Medicine and Therapeutics is an international, peer-reviewed, open access journal focusing on health, pathology, and treatment issues specific to the adolescent age group. All aspects of health maintenance, preventative measures and disease treatment interventions are addressed within the journal and practitioners from

\section{Dovepress}

all disciplines are invited to submit their work as well as healthcare researchers and patient support groups.. The manuscript management system is completely online and includes a very quick and fair peerreview system. Visit http://www.dovepress.com/testimonials.php to read real quotes from published authors. 